\title{
Publication 972
}

\section{Control of}

\section{Rats and Mice}

BY C. R. TWINN . ENTOMOLOGY DIVISION 



\title{
CONTROL OF RATS AND MICE
}

\author{
by \\ C. R. TWINN \\ Veterinary and Medical Entomology Unit \\ Entomology Division, Ottawa
}

\section{RATS}

The Norway rat" (Figure 1) is the most formidable and the most widely distributed of the species of rodents that destroy or contaminate food, damage buildings and equipment, and carry disease. It is also known as the brown, house, barn, sewer, and wharf rat. This species invades houses, stores, warehouses, granaries, markets, restaurants, bakeries, and other places where food is handled or stored. It attacks all kinds of food, such as grains, meats, fruits, and vegetables, and may destroy other materials such as fabrics and leather goods. It sometimes causes destructive fires by gnawing the insulation off electrical connections. Another species of domestic rat common in many parts of the world, but not in Canada, is the black or roof rat $^{3}$.

Besides destroying enormous amounts of food supplies, the rat is a serious menace to public health. Bubonic plague, one of the most devastating of human diseases has been carried by the rat all over the world. In the fourteenth century it is estimated that about 25 million people died in Europe from the Black Death, as this disease was called, and two million deaths are stated to have occurred during the epidemic of the plague in India in 1907. Bubonic plague is transmitted from rats to humans by fleas, and modern methods of preventing its spread involve the most vigorous eradication of rats and the prevention of their landing in seaports from ocean-going vessels. Endemic or murine typhus fever is also harbored by rats and may be transmitted to man by fleas. The serious disease known as trichinosis, caused by the trichinella worm, affects rats. Pigs may become diseased from eating infected rats, and the organism may be transmitted to man when imperfectly cooked flesh from such diseased hogs is eaten. Salmonellosis, a bacterial disease characterized by diarrhoea, abdominal cramps, fever, and occasional nausea and vomiting, may be transmitted by infected rats contaminating food with their urine and faeces. Hemorrhagic jaundice, or Weil's disease, and ratbite fever are two other diseases known to be transmitted by rats.

Rats are most likely to be numerous in establishments that handle or store food. They also favor buildings that are poorly constructed or maintained and where suitable harborages abound. Most rats stay close to their harborages so long as the food supply is adequate, and establish regular

\footnotetext{
${ }^{1}$ Revision of Canada Department of Agriculture War-time Production Series Special Pamphlet No. 33 .

${ }^{2}$ Rattus norvegicus (Erxleben).

${ }^{3} R$, rattus (L.) and subspecies or varieties.
} 
runways between their hiding places and food and water. These runways are usually alongside walls, along pipes, between closely stacked merchandise, and in similar places where concealment is easy. In heated buildings where food and shelter are available, they breed throughout the year and under favorable conditions may produce six or more litters annualiy. Each litter may contain from six to fourteen young.

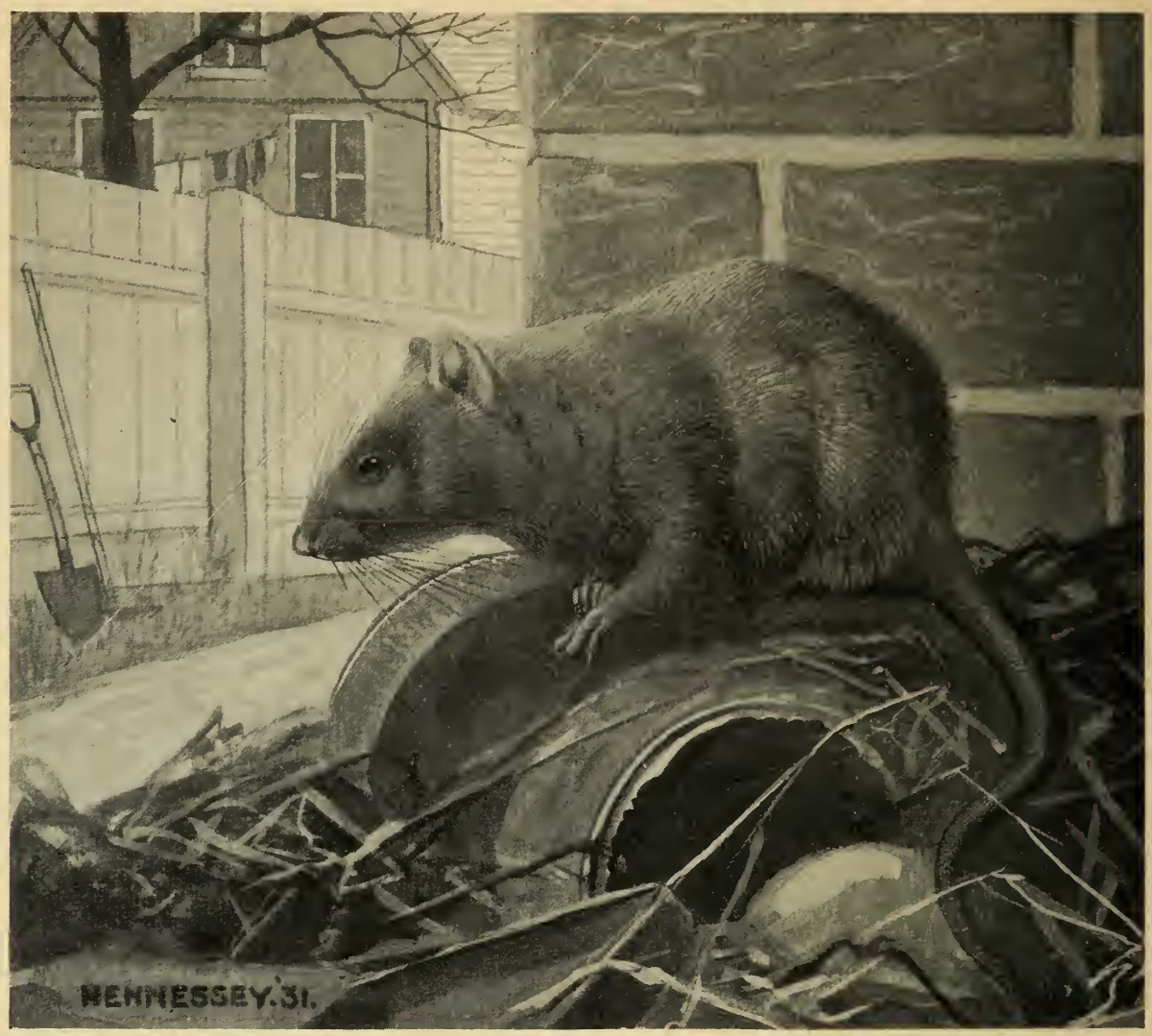

Figure 1. The Norway rat.

\section{CONTROL}

\section{Preventive Measures}

To eradicate rats it is essential to maintain good housekeeping and to prevent refuse and garbage from accumulating. Keep waste food and other garbage in rat-proof metal containers until disposed of by burning or by other sanitary method. Open garbage dumps are an important harborage of rats and of flies, both important agents in the spread of disease. Instead of using open dumps, burn combustible garbage in efficient incinerators. Noncombustible refuse may be used as sanitary land fill in low-lying areas, the refuse being covered with two feet of soil to exclude rats.

Make buildings rat-proof, the best material for this purpose being concrete. In constructing and maintaining buildings in which food is kept and rats are likely to occur, pay special attention to the following: Block off or stop up 
all actual or potential entrances with concrete or other materials that rats cannot penetrate, especially in foundations and where drain and other pipes enter. Have doors and windows fit tightly and bind them with metal strips where rats are likely to gnaw through. Put strong wire screens in front of doors and windows on the ground floors. In buildings without basements replace wooden floors next to the ground with concrete, and have retaining walls extending two feet underground to prevent burrowing under the floor from outside. Eliminate or deny the rats access to other harborages in and about buildings.

\section{Poisoning}

The most efficient means of destroying rats is poisoned bait. However, great care must be exercised to protect humans, pets, and other domestic animals against accidental poisoning. Among the poisons used are warfarin, red squill, antu, zinc phosphide, arsenic, thallium sulphate, and sodium fluoroacetate (1080). Of these, warfarin is one of the most suitable for general use, and 1080 the most dangerous. The last four chemicals named should be used only by trained, experienced persons, such as competent pest control operators or exterminators, and are not discussed further here.

Warfarin.-This chemical ${ }^{t}$ is a most effective ratkiller. It is an anticoagulant that causes painless death by internal bleeding. It is available commercially under various brand names at a concentration of 0.5 per cent. For use, mix 1 pound of this material thoroughly with 19 pounds of bait, usually fresh ground corn meal, rolled oats, or mixtures of these two cereals. Smaller or larger amounts may be mixed in the same proportions. At this concentration in the bait, namely, 0.025 per cent, warfarin is tasteless and odorless and is readily accepted by rats. Place the baits in amounts of two to several ounces in places frequented by the rats but inaccessible to children and domestic animals. Place them in rat runways and harborages, preferably under cover, where rats are more likely to take them than if they are placed in the open. Be sure to use enough bait for all the rats infesting the premises. Rats do not become bait-shy with warfarin, and the baits may be renewed at intervals if necessary. Before distributing the baits, so far as possible, remove or cover other sources of food available to the rats. Several days to two weeks may be required to get rid of most or all of the rats in a building.

Warfarin would probably kill domestic animals and man if taken in sufficient quantities over a prolonged period of time, but as it is used at a low concentration and the bait material is unattractive to children and pets, it is one of the safest ratkillers to use in dwellings and food-handling establishments.

Other anticoagulant chemicals, effective against rats, that have recently become available are sold commercially under the brand names of Pival, Pivalyn, and Tormorin.

Red Squill.-This material is obtained from the bulbs of a lily-like plant that grows in the Mediterranean region. It approaches the anticoagulants (e.g., warfarin) in freedom from hazard of accidental poisoning, as it has a bitter taste objectionable to man and to many domestic animals and, moreover, causes vomiting in most animals other than rats. As it lacks uniform toxicity when imported, purchasers should insist on a guaranteed minimum toxicity of $500 \mathrm{mg} . / \mathrm{kg}$. A weakness of red squill is that rats that have taken a sublethal dose refuse to eat any more of the poisoned material. Hence, baiting with it must be intensive over a short period of time. Other poisons or other methods must be used to kill any survivors. For use, thoroughly mix 1 pound of red squill with 9 pounds of suitable bait materials, such as fresh ground

4 3-(alpha-acetonylbenzyl)-4-hydroxycoumarin. 
meat or fish, or cereal, or smaller quantities in the same proportions. Before mixing it with the meat or fish make it into a thin smooth paste with a little water. Mix it dry with cereals, such as oatmeal or corn meal, add sweet milk or water, and stir to a mushy consistency.

Preferably use fish, meat, and cereal baits at the same time, to ensure that all the rats may be attracted and eat of the poisoned material. Before distributing the baits, remove or cover other sources of food available to the rats. Put out the baits in late afternoon, in small portions, in and about places frequented by the rats. After three days, collect and destroy uneaten baits.

Antu.-Antu $\overline{5}$ ranks next to warfarin, other anticoagulants, and red squill in safety to man for use as a ratkiller. However, it is highly toxic to dogs, cats, pigs, and young chicks. It is specific against the Norway or brown rat but ineffective against other rodents. It is used at a concentration of 1 per cent with a bait attractive to rats. It kills the rats by causing body fluids to accumulate in the chest cavity, literally drowning the animals. Death usually occurs in 12 hours to 2 days. A disadvantage of antu is that rats rapidly develop bait-shyness to it; moreover, those that receive a sublethal dose build up a tolerance for it. Hence, antu should be used only against rats not previously exposed to it, and the initial baiting should be done throughout the infested area and include enough material to poison all the rats present. Put the baits in places where they will be readily available to the rats but not to children, pets, or other domestic animals. After two or three days remove and destroy uneaten baits. Later, if an infestation persists, use another ratkiller or other methods.

\section{Gassing}

Calcium Cyanide.-Rats may be destroyed in their burrows by means of calcium cyanide. This material, which is sold in dust and in granular form, generates hydrocyanic acid gas when exposed to the air. Both the solid and the gas are extremely poisonous to humans, as well as to rats and other animal life, and should be used only by competent persons fully aware of their dangerous properties and in accordance with any provincial or local regulations that may be in force. Do not use it indoors or near occupied buildings. Granular calcium cyanide may be placed in the burrows with a spoon. Place a teaspoonful in the mouth of each burrow and seal all openings. Best results are obtained by using the dust form with a dusting pump with a flexible hose attached. Tightly plug all but one of the entrances to a series of burrows to retain the gas, and, after forcing the material in with several strokes of the pump, seal the remaining hole.

Carbon Monoxide.-Carbon monoxide may also be used to kill rats in their burrows. This may be done by directing the exhaust fumes from a gasoline engine into the entrance of a burrow with a hose, after carefully sealing other exits with earth. Run the engine at moderate speed and direct the fumes into the burrow for about ten minutes, afterwards sealing the hole. This gas, too, is very poisonous to man and other animals.

\section{Trapping}

Traps are useful for killing or capturing rats in dwellings or in other places where only a few are present. When rats are numerous, preferably use poisoned baits and resort to traps only as a final clean-up measure. The best traps are those of the spring or guillotine type. The traps may be baited with any of the foods attractive to rats, such as bacon or other meat, fish,

5 Alpha-naphthylthiourea. 
or cheese. Fasten the bait firmly to the trigger of the trap and place the latter in a natural runway of the rodents. Spring traps may be used effectively without bait by placing them in runways formed by leaning boards against walls and covering the traps with pieces of cheesecloth, sawdust, or other light material to hide them. Several other effective types of traps are available.

\section{MICE}

The common house mouse ${ }^{6}$ (Figure 2), like its larger relative the rat, destroys or contaminates food and is the known or suspected carrier of several diseases that are communicable to man. It has a short life of up to about 18 months but is a prolific breeder, having as many as eight litters a year and an average of five young per litter. If food and shelter are adequate, house mice usually do not venture more than 10 to 20 feet from their nesting places.

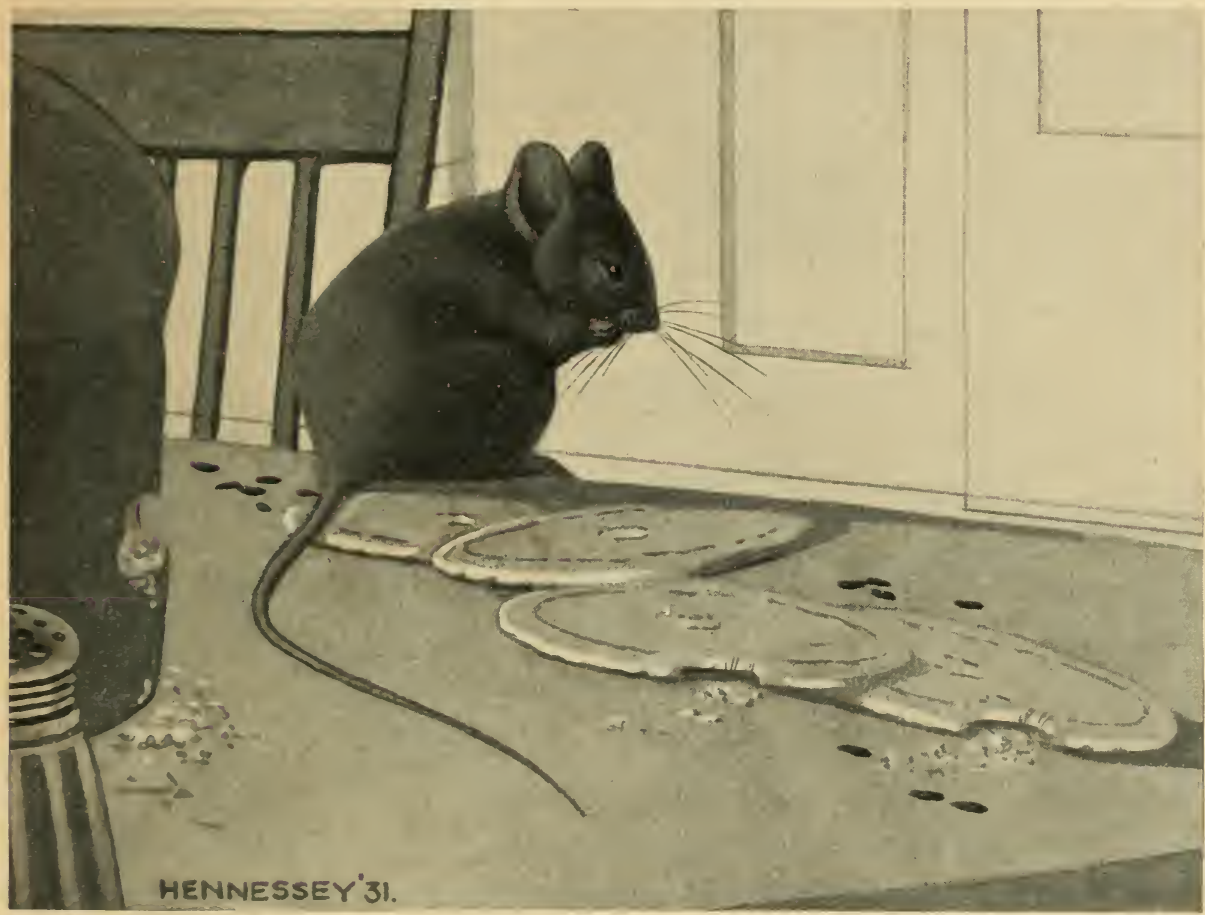

Figure 2. Common house mouse.

\section{CONTROL}

\section{Trapping}

The well-known guillotine or snap trap is the most satisfactory. Bait the traps with cheese, fried bacon, peanut butter, cake, or other attractive food. A combination bait of two or more of these may be used. If the animals are abundant, use a number of traps. Place them near holes and along runways and in other places known to be frequented by the mice. 


\section{Poisoning}

Warfarin and other anticoagulant rodenticides are effective when mixed and used in poisoned baits in the same manner as recommended for rats. It may take as long as several weeks to obtain complete control of mice in a building. If necessary, renew the baits at intervals. Mice are also very susceptible to DDT. Powders containing from 10 to 50 per cent of DDT have been found to kill mice. A 25 per cent DDT powder has given good results in practical pest control work. Apply the powder with a dust gun into mouse holes, along runways, and on other surfaces where the mice run. In doing so take care not to contaminate food or food utensils with the powder.

Both warfarin and DDT are rather slow-acting poisons. Strychnine is fast-acting, but has the disadvantage of being highly poisonous to other animals and man. However, commercial preparations of strychnine-coated seeds with directions for use on the container labels are available, and may be used where there is no danger of accidental poisoning.

For further information write to the Veterinary and Medical Entomology Unit, Canada Department of Agriculture, Science Service Building, Ottawa.

(A few brand names are used in this publication because chemical names for the materials are difficult for general use and there are no official common names for them.)

Edmond Choutier, C.M.G., O.A., D.S.P., Queen's Printer and Controller of Stationery, Ottawa, 1956 